\title{
3 Research Square \\ Characteristics And Outcomes of Perforating Trauma With Intraorbital Foreign Body
}

Hui Ren

Eye and ENT Hospital of Fudan University

Xiaobing $\mathrm{Hu}$

Huashan Hospital Fudan University

Min Zhou

Eye and ENT Hospital of Fudan University

\section{Yongheng Huang}

Eye and ENT Hospital of Fudan University

\section{Diwen Guo}

Tongren Hospital Jiaotong University

\section{Rui Jiang}

Eye and ENT Hospital of Fudan University

Jiang Qian ( $\sim$ qianjiang58@163.com )

Eye and ENT Hospital, Fudan University https://orcid.org/0000-0002-8504-7857

\section{Research article}

Keywords: peforating trauma, orbital foreign body

Posted Date: August 23rd, 2019

DOl: https://doi.org/10.21203/rs.2.13519/v1

License: (c) (1) This work is licensed under a Creative Commons Attribution 4.0 International License.

Read Full License 


\section{Abstract}

Background To evaluate the characteristics and outcomes of patients with perforating trauma with intraorbital foreign body (IOrbFb). Methods Retrospective chart review of 31 consecutive patients with perforating trauma and IOrbFb treated in Eye and ENT Hospital of Fudan University from 2014 to 2018. Results $30(96.8 \%)$ patients were male and $1(3.2 \%)$ was female. The ocular trauma score (OTS) was 1 in 18 (58.1\%) patients, 2 in 8 (25.8\%) patients and 3 in $5(16.1 \%)$ patients. At the time of the last follow-up, the visual acuity was 20/40 or better in $3(9.7 \%)$ patients, $6(19.4 \%)$ patients was between 20/50-20/200, $6(19.4 \%)$ was between $20 / 200$ or worse, a total of $16(51.6 \%)$ patients was no light perception and 14 (45.2\%) patients underwent evisceration/enucleation. Conclusions The prognosis of perforating trauma with IOrbFb is closely related to OTS. Removal of IOrbFbs is safe with current orbital surgery techniques. An emphasis on education and protective eyewear use would be helpful in reducing these injuries.

\section{Introduction}

Perforating trauma with intraorbital foreign bodies (IOrbFb) is a kind of ocular traumas that ophthalmologists would encounter in the emergency room. Whereas there are scarce literature targeting this kind of ocular trauma and summarizing the characteristics and outcomes of patients with perforating trauma with IOrbFb. And there are still some controversies against the indications for surgical removing of IOrbFb. Here we summarized our experience with treating perforating trauma with IOrbFb and determine the prognostic indicators of visual outcome.

\section{Methods}

This study was conducted in accordance with the Declaration of Helsinki, and the approval was obtained from the institutional review board. A consecutive series of perforating trauma with IOrbFb who underwent surgery in Eye and ENT hospital of Fudan University from 2014 to 2018 were retrospectively evaluated. Medical records were reviewed and clinical data including trauma history, computed tomography (CT) and magnetic resonance imaging (MRI) images, B scan, size and location of IOrbFb, initial and last visual acuity (VA), length of follow-up were collected. Definition of perforating trauma and calculated ocular trauma score (OTS) followed the Birmingham Eye Trauma Terminology (BETT) and Ocular Trauma Classification Group guidelines ${ }^{1,2}$. Surgical approach for IOrbFb removal was dependent on location of IOrbFb in orbit.

\section{Results}

A total of 31 patients was included in this study, among which 30 (96.8\%) were male and 1 was female (3.2\%). The average age was 39 years (ranging from 19-57 y). 16 patients had primary perforation repair in local hospitals and the rest 15 were treated in our hospital after the initial trauma. The initial vision after the trauma was poor in most of the patients, 15 (48.4\%) was no light perception (NLP), 10 (32.3\%) was between light perception to HM, $2(6.5 \%)$ was between $1 / 200$ to $19 / 200$, and only $4(12.9 \%)$ was 
between $20 / 200$ to $20 / 50$. The average duration between injury to surgical removal of IOrbFbs was 25 days, ranging from 20 hours to 5 months. 20 (64.5\%) IOrbFbs were iron pieces, 2 (6.5\%) were steel, 1 was (3.2\%) aluminum, 1 (3.2\%) IOrbFb was nail, 1 (3.2\%) was wood, 1 (3.2\%) was stone, 3 (9.7\%) were from detonator explosion, 1 (3.2\%) was from car accident and 1 (3.2\%) was from shotgun. The baseline demographics was showed in Table 1.

Most patients needed many additional surgeries during their ocular rehabilitation, the average number of surgeries was 2.6 (ranging from 1 to 5 times). 3 (9.7\%) patients had primary evisceration because the eyes were severely injured to the point where sufficient tissue for repair is not present ${ }^{3} .10(32.3 \%)$ patients had secondary evisceration/enucleation for blind atrophic eye during the first 6 months after the initial trauma, and 1 patient was eviscerated for combined panophthalmitis. IOrbFb could not be located in 1 (3.2\%) patient during the surgery, 2 (6.5\%) patients had multiple IOrbFbs from shotgun or detonator explosion and had some of the IOrbFbs removed, the rest 28 (90.3\%) had their IOrbFbs removed.

The size of IOrbFbs varied (Table 2) with an average size of $9 \mathrm{~mm}$, ranging from $2 \mathrm{~mm}$ to $35 \mathrm{~mm}$ (Figure 1). And the position of the IOrbFbs was shown in Table 2. 10 IOrbFbs were attached to the posterior sclera, 3 were embedded in the optic nerve, 7 were found in the intraconal space, 7 were near the optic nerve (the definition of near was the IOrbFbs locating less than $2 \mathrm{~mm}$ away from the optic nerve in CT scan) and 4 were protruding from the posterior sclera to the orbit and there was still some part of the foreign body in the eye. The average raw points of OTS of these 31 patients was 40.7 , ranging from 8 to 76. OTS was 1 in 18 (58.1\%) patients, 2 in 8 (25.8\%) patients and 3 in $5(16.1 \%)$ patients. The 17 patients with their injured eyeballs preserved were followed 1 to 44 months, 15.2 months on average. At the time of the last follow-up, the visual acuity was $20 / 40$ or better in $3(9.7 \%)$ patients, $6(19.4 \%)$ patients was between $20 / 50-20 / 200,6$ (19.4\%) was between 20/200 or worse. 14 (45.2\%) patients underwent evisceration/enucleation, besides the 14 patients 2 (6.5\%) additional patients had a final visual acuity of no light perception.

\section{Discussion}

There is a widely accepted opinion that posteriorly located inorganic IOrbFbs should be left alone, unless they are causing significant orbital complications because removal of the foreign body is generally complicated because of difficulty in detecting it intraoperatively ${ }^{4-8}$. However, IOrbFbs embedded in the sclera may develop siderosis ${ }^{9}$ and ferromagnetic IOrbFbs left in orbit may prevent patients from undergoing MRI in future. Even though these materials can remain harmless for years, they can cause serious ocular injuries when exposed to strong magnetic forces ${ }^{9}$. Indications for IOrbFbs removal in this case series were IOrbFbs partially in the eye or embedded in the sclera or near the optic nerve. Those 7 patients with IOrbFbs in the intraconal space had their IOrbFbs removed simultaneously when evisceration/enucleation and orbital implant implantation surgeries were performed. And the average size of IOrbFb was $9 \mathrm{~mm}$ which was not small comparing to the average $3 \mathrm{~mm}$ size in intraocular foreign bodies (IOFBs $)^{10}$. Bigger IOrbFbs might cause more damage comparing to smaller ones but it makes the 
localization of the IOrbFbs easier during the surgeries. And 17 (54.8\%) patients' IOrbFbs in this case series were in a place of anatomic landmark such as sclera or optic nerve and 7 (22.6\%) were near the optic nerve. Surgical approach for IOrbFbs removal is determined based on size and location of IOrbFbs in orbit. IOrbFbs embedded in the sclera especially temporal sclera can be accessed though transconjunctival approach if they were within $20 \mathrm{~mm}$ from the limbus. Otherwise deeper temporal IOrbFbs can be removed through lateral orbitotomy (representative images shown in Figure 2). IOrbFbs can be accessed by exploring from entry site or through fistula pathway, if cutaneous fistula is present. Sometimes IOrbFbs are encapsulated by fibrous scars in orbit, in such cases, it is helpful to use operation microscope and to follow scar tissue ${ }^{11}$. No complications from surgical removal of IOrbFbs was encountered in the study.

There are several factors associated with the prognosis of perforating trauma with orbital foreign body. The OTS has been recommended as a method to classify ocular injuries and predict prognosis ${ }^{2}$. In general, our data showed good correlation between increasing OTS and improved visual acuity outcome. $5(100 \%)$ patients' ultimate visual acuity was over $20 / 200$ when OTS was 3 , and $4(50 \%)$ patients was over 20/200 when OTS was 2. While 17 (94.4\%) was NLP when OTS was 1. For IOFBs, the extent of ocular injury and visual prognosis depends on the IOFB size, the zone of the injury ${ }^{12-17}$. It is similar for perforating trauma with IOrbFbs because those foreign bodies were IOFBs before they reached the orbit. The loss of vision is generally related to the initial injury and there are no vision decrease after the removal of IOrbFbs, which is consistent with previous studies ${ }^{5,9}$. The improvement in visual acuity seen in the patients could be attributed to resolution of vitreous hemorrhage and retinal edema.

Wounds to the periocular region are highly vascular and therefore are rarely associated with infection. There was only 1 patient had consecutive infection because a trans-scleral foreign body was left in situ for 4 days before referring to our hospital. And no infection was found in the rest of the patients. No sympathetic ophthalmia was found in these patients during the follow-up.

Accidents are significantly more common among men, self-employed individuals, and workers with no college education ${ }^{4}$. Many of these injuries that occur at work could be prevented with the proper use of safety glasses or other protective equipment.

\section{Conclusion}

The prognosis of perforating trauma with orbital foreign body is closely related to OTS. Removal of IOrbFbs is safe with current orbital surgery techniques in most circumstances.

\section{Abbreviations}

IOrbFb: intraorbital foreign bodies; OTS: ocular trauma score; VA: visual acuity; NLP: no light perception; HM: hand motin; IOFBs: intraocular foreign bodies 


\section{Declarations}

\section{Ethics approval and consent to participate}

The study was approved by the Institutional Review Board of Eye and ENT Hospital of Fudan University, and adhered to the tenets of the Declaration of Helsinki. This article does not contain any studies with animals performed by any of the authors. Written informed consent was obtained from all patients.

\section{Consent for publication}

Not applicable. The patient data was de-identified and consent was not required. National guidelines have established that studies such as this doesn't require consent.

\section{Availability of data and materials}

All of our detailed information were collected from doctor's workstation of Eye and ENT Hospital of Fudan University, which is read-only, so we are sorry that the detailed data can't be shared.

\section{Competing Interests}

None declared.

\section{Funding}

National Natural Science Foundation of China (81300805)

\section{Authors' contributions}

$\mathrm{HR}$ and XBH carried out the collection of clinical data and drafted the manuscript. MZ and RJ participated in the design of the study and performed the statistical analysis. YHH and DWG followed all the patients and collected some data. JQ conceived of the study, and participated in its design and coordination and helped to draft the manuscript. All authors read and approved the final manuscript.

\section{Acknowledgements}


None.

\section{References}

1. Kuhn F, Morris R, Witherspoon CD. Birmingham Eye Trauma Terminology (BETT): Terminology and classification of mechanical eye injuries. Ophthalmol Clin North Am. 2002;15:139-143.

2. Kuhn F, Maisiak R, Mann L, et al. The Ocular Trauma Score (OTS). Ophthalmol Clin North Am. 2009;15:163-165.

3. Savar A, Andreoli MT, Kloek CE, et al. Enucleation for Open Globe Injury. Am J Ophthalmol. 2009;147:595-600.

4. Kanoff JM1, Turalba AV, Andreoli MT, et al. Characteristics and Outcomes of Work-Related Open Globe Injuries. Am J Ophthalmol 2010,150:265-269.

5. Finkelstein M, Legmann A, Rubin PAD. Projectile metallic foreign bodies in the orbit. A retrospective study of epidemiologic factors, management, and outcomes. Ophthalmology 1997;104:96-103.

6. Michon J, Liu D. Intraorbital foreign bodies. Semin Ophthalmo/ 1994;9:193-9.

7. Holt GR, Holt JE. Management of orbital trauma and foreign bodies. Otolaryngol Clin North Am 1988;21:35-52.

8. Go"nu“I E, Akbo“ru“ M, Izci Y, Timurkaynak E. Orbital foreign bodies after penetrating gunshot wounds: retrospective analysis of 22 cases and clinical review. Minim Invas Neurosurg 1999;42:207-11.

9. Fulcher TP, McNab AA, Sullivan TJ. Clinical features and management of intraorbital foreign bodies. Ophthalmology 2002;109:494-500.

10. Kuhn F, Pieramici DJ. Intraocular foreign bodies, In: Ferenc K, Pieramici D (eds) Ocular Trauma: Principles and Practice. New York, Thieme; 2002; pp 235-263.

11. Orcutt JC. Orbital foreign bodies. In: Linberg JV, editor. Oculoplastic and Orbital Emergencies. Norwalk: Appleton\&Lange;1990; p. 183-97.

12. Loporchio D, Mukkamala L, Gorukanti K, et al. Intraocular foreign bodies: A review Surv Ophthalmol 2016;61:582-96.

13. Dolezalova J. Penetrating intraocular injuries caused by foreign bodies of organic origin. Cesk Slov Oftalmol 2001;57:381-6.

14. Essex RW, Yi Q, Charles PGP, et al. Post-traumatic endophthalmitis. Ophthalmology 2004;111:201522.

15. Jonas JB, Knorr HL, Budde WM. Prognostic factors in ocular injuries caused by intraocular or retrobulbar foreign bodies. Ophthalmology 2000;107:823-8.

16. Knyazer B, Levy J, Rosen S, et al. Prognostic factors in posterior open globe injuries (zone-lll injuries). Clin Experiment Ophthalmol 2008;36:836-41. 
17. Woodcock MG, Scott RA, Huntbach J, et al. Mass and shape as factors in intraocular foreign body injuries. Ophthalmology 2006;113:2262-9.

\section{Tables}

Table 1 Peforating Trauma with Intraorbital Foreign Body Baseline Data

Total Peforating trauma with orbital foreign body $(\mathrm{N}=31)$

Demographics

$\begin{array}{lc}\text { Male, } \mathrm{n}(\%) & 30(96.8 \%) \\ \text { Average age, years (range) } & 39(19-57) \\ \text { Initial vision, } \mathrm{n}(\%) & \\ 20 / 200 \text { to } 20 / 50 & 4(12.9 \%) \\ \text { 1/200 to } 19 / 200 & 2(6.5 \%) \\ \text { Light perception/HM } & 10(32.3 \%) \\ \text { No light perception } & 15(48.4 \%) \\ \text { Mechanism of injury, } \mathrm{n}(\%) & \\ \text { Nail } & 1(3.2 \%) \\ \text { wood } & 1(3.2 \%) \\ \text { stone } & 1(3.2 \%) \\ \text { detonator explosion } & 3(9.7 \%) \\ \text { car accident } & 1(3.2 \%) \\ \text { shotgun } & 1(3.2 \%) \\ \text { other projectiles } & 23(74.2 \%)\end{array}$

Table 2 Location and Size of Intraorbital Foreign Bodies in This Series

Attached to the posterior sclera (10) Embedded in the optic nerve (3)

Intraconal space (7) Near the optic nerve (7)

In the orbit and the eye simultaneously (4)

Size of foreign bodies, $n$

$<5 \mathrm{~mm}$

$9(29 \%)$

$5-10 \mathrm{~mm}$

$14(45.2 \%)$

$10-20 \mathrm{~mm}$

$5(16.1 \%)$

$>20 \mathrm{~mm}$

$3(9.7 \%)$

Table 3 Outcomes for Peforating Trauma with Intraorbital Foreign Body ( $\mathrm{N}=31)$ 
Final vision, $\mathrm{n}(\%)$

$20 / 40$ or better

$3(9.7 \%)$

20/50-20/200

$6(19.4 \%)$

$20 / 200$ or worse

No light perception

Average follow-up for patients with eyeball preserved, months (range) 15.2 (1 to 44)

Additional surgeries needed, $\mathrm{n}$

Lensectomy

Vitrectomy

Eviseration/Enucleration
1

22

14

\section{Figures}

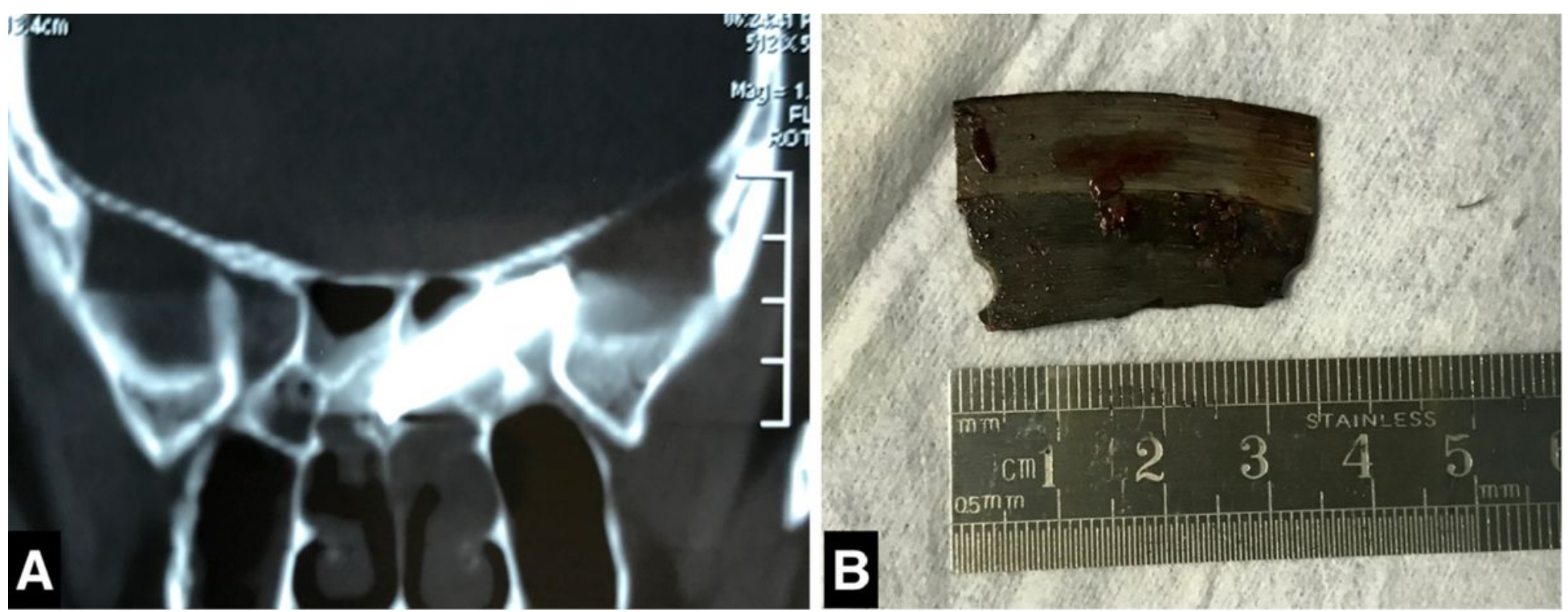

\section{Figure 1}

Figure 1 Representative case example of perforating trauma with intraorbital foreign body. Com-puted Tomography scan showed the foreign body.(A) Metallic foreign body removed from the eye. (B) 

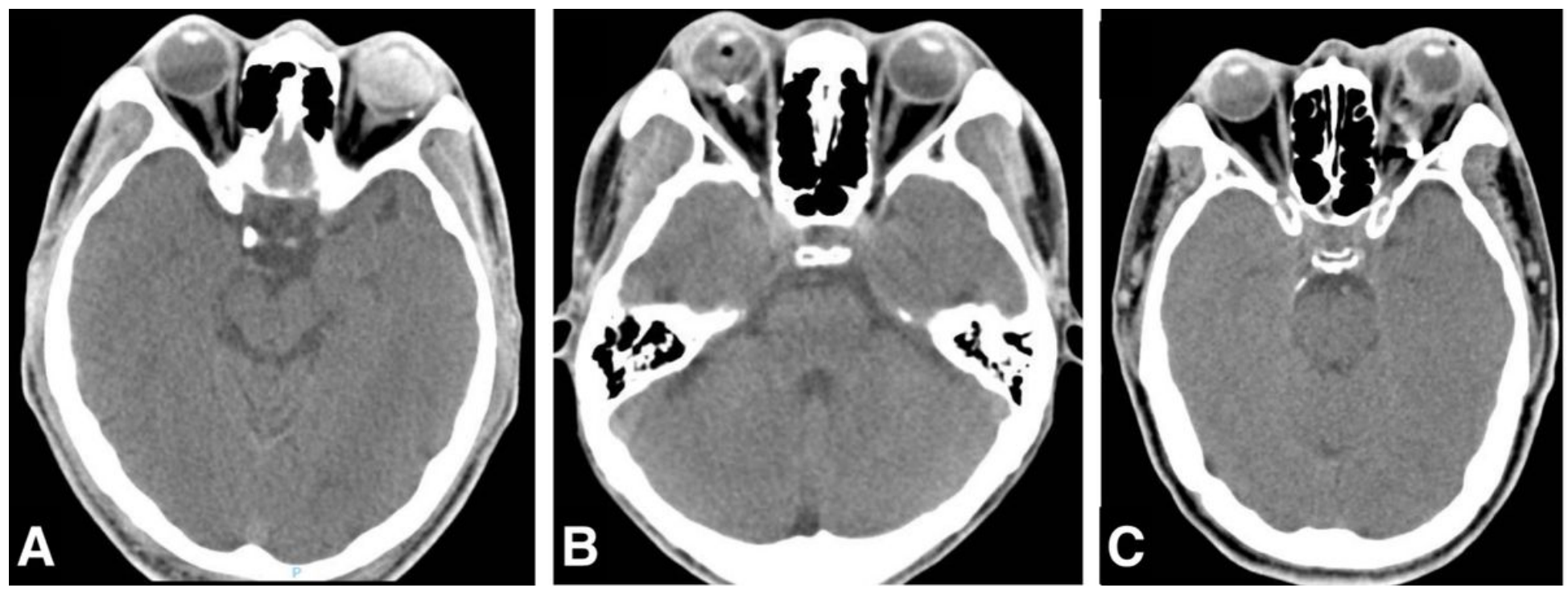

Figure 2

Figure 2 Representative cases of intraorbital foreign bodies in different locations. IOrbFb embed-ding in the temporal sclera was removed through transconjunctival approach. (A) IOrbFbs near the optic nerve were removed through lateral orbitotomy. $(B, C)$ 